\title{
A construção do Paraná "Europeu"
}

\section{Leonardo David Micheleto ${ }^{1}$}

RESUMO: Esse trabalho consiste no estudo da construção do pensamento de que o Paraná é um estado "europeu", pensamento este que muitas vezes se passa como realidade para parte da população paranaense, título até ostentado com orgulho para alguns. Mas como é construída essa realidade? Quem a constrói? Em busca dessas respostas, fomos atrás dos autores consagrados, literatos intelectuais por detrás dessa ideia. Os dois principais analisados são Nestor Vítor e Wilson Martins. Pesquisamos suas biografias e suas famílias, de modo a desvelar a que grupo social pertencem, para relacionarmos com o estilo de pensamento que perpretam, usando a metodologia de Ricardo Costa de Oliveira e de Karl Manheimm. Utilizamos o estudo de Stuart Hall para pensarmos como a construção de "comunidades imaginadas" e a "invenção das tradições" atuam na cultura não somente no nível nacional, mas também no regional, gerando uma nova relação com o "Outro" nessa tentativa de diferenciação.

Palavras-chave: Imigração Paraná. Wilson Martins. Nestor Victor.

\section{The construction of the "European"}

\begin{abstract}
This work consists of the study of the construction of the thought that Paraná is a "European" state, a thought that often happens as a reality for part of the population of Paraná, a title even proudly displayed for some. But how is this reality constructed? Who builds it? In search of these answers, we went after the established authors, intellectual writers behind this idea. The two main analyzed are Nestor Vítor and Wilson Martins. We researched their biographies and their families, in order to unveil what social group they belong, in order to relate to the style of thought they interpret, using the methodology of Ricardo Costa de Oliveira and Karl Manheimm. We use Stuart Hall's study to think how the construction of "imagined communities" and the "invention of traditions" operate in culture not only at the national but also at the regional level, generating a new relationship with the "Other" in this attempt to differentiate.
\end{abstract}

Keywords: Immigration Paraná. Wilson Martins. Nestor Victor.

- Enviado em 01/05/2017

- Aprovado em 17/05/2017

\footnotetext{
1 Graduado em História pela Universidade Federal do Paraná; Mestrando em Sociologia pela UFPR; possui bolsa pela CAPES. Uma versão preliminar desse texto foi apresentada no VIII Seminário Nacional de Sociologia e Política realizado de 17 a 19 de maio de 2017 na UFPR. E-mail: leonardo_micheleto@hotmail.com
} 


\section{INTRODUÇÃO}

A ideia de que o Paraná é um Estado "europeu" é uma ideia que existe há tempos, e que ainda prevalece em amplos setores da sociedade paranaense. Um fato que evidencia isso é o da vitória de Rafael Greca de Macedo nas eleições para prefeito de Curitiba em 2016. Greca, em suas gestões anteriores como prefeito, republicou livros dos autores que lançaram essas ideias no campo da literatura. Além disso, inaugurou diversos monumentos, parques e homenagens à contribuição da imigração europeia em Curitiba, e nada para as outras culturas². Com sua campanha "Volta Curitiba", Greca queria se referir a qual narrativa sobre o passado dessa cidade? Sendo essa a campanha vitoriosa, podemos ver que esse discurso ainda é muito forte na população, levando em conta também a quantidade grande de votos nulos e brancos e a estrutura geral de que sua campanha tinha em detrimentos das outras. Apesar disso, podemos perceber que a ideia do Paraná branco e europeu permanece forte. Mas quais são as origens desse pensamento? Para responder a essas perguntas, pesquisamos sobre os literatos mais famosos na construção dessa ideia: Wilson Martins e Nestor Vítor.

Wilson Martins escreveu a obra Um Brasil Diferente, em 1955, com o intuito de, inspirado em Gilberto Freyre, trazer o que diferencia o paranaense e o Paraná do restante do Brasil, através do estudo da aculturação do imigrante europeu. Por sua vez, Nestor Vítor escreveu em 1912 o título A Terra do Futuro, um livro de viagem financiado pelo então Presidente da Província para exaltar as terras paranaenses.

A partir da busca sobre as biografias e trajetórias desses dois autores, traçaremos um paralelo com as ideias por eles apresentadas, sua coerência com a História do Paraná e suas visões sobre a colonização do território.

Debateremos ainda sobre as ideias de cultura e de racismo, tal como as concebeu o sociólogo Stuart Hall, pois a questão étnica é o eixo central nas obras de Wilson Martins e de Nestor Vítor.

\footnotetext{
${ }^{2}$ Moraes, Pedro Rodolfo Bodê de, and Marcilene Garcia de Souza. "Invisibilidade, preconceito e violência racial em Curitiba." Revista de Sociologia e Política 13 (1999): 7-16.
} 


\section{TRAJETÓRIAS E CONSTRUÇÃO DO PENSAMENTO}

Segundo o próprio Wilson Martins ${ }^{3}$, nasceu em São Paulo em 3 de março de 1921. Mudouse para Curitiba com nove anos, em 1930. Antes disso, já tinha o costume ler, tendo feito o primário em uma escola rural mista chamada Martinópolis - segundo ele, sem conexões familiares com os proprietários. Sua família era pobre e seu pai era professor, o que fez com que o hábito da leitura se fizesse presente antes mesmo de Wilson entrar na escola. Inclusive seu pai foi professor na escola da Fazenda Marinópolis ${ }^{4}$. Em Curitiba, foi aprovado e estudou no Ginásio Paranaense. Aos dezesseis anos, começou a trabalhar como revisor da Gazeta do Povo, emprego conseguido pelo seu pai, através de contato com o Professor Doutor Milton Carneiro, que tinha boas ligações com o jornal, o mais importante do Paraná à época. Trabalhou também para o jornal "O Estado", nos tempos de Estado Novo, em seguida no jornal "Diário dos Campos", de Ponta Grossa.

Formou-se em Direito pela Universidade Federal do Paraná em 1943. Na década de 1940 começou a trabalhar como locutor na Rádio Clube Paranaense, a única da cidade, o que a fazia ter grande importância como meio de comunicação e artes. Na mesma época, começou a escrever colunas de crítica literária para alguns jornais, o que viria a ser seu principal reconhecimento, sendo em determinada época tido como o melhor crítico literário do Brasil. Antes disso, porém, muita coisa aconteceu. Foi contratado para ser chefe de gabinete do interventor Manoel Ribas, que havia designado por Getúlio Vargas para o governo do Paraná. Segundo Martins, Manoel Ribas era como um "pai adotivo" para ele, tendo trabalhado juntos por um ano e meio, sendo designado, no final dessa jornada, para o Departamento Estadual de Cooperativismo.

Em 1947, ganhou uma bolsa para estudar na França por dois anos. Na volta, em 1952, assumiu o cargo de juiz de Direito, o qual permaneceu por dez anos. Por dez anos também permaneceu como professor de Literatura Francesa na Universidade Federal do Paraná. Foi nessa

\footnotetext{
3 Disponível em http://www.jws.com.br/2017/03/memoria-paranaense-entrevista-com-wilson-martins-criticoliterario/. Acessado em 30/04/2017.

${ }^{4}$ Quadros, Claudia Irene de, and Mônica Kaseker. "Wilson Martins: das ondas do rádio às críticas literárias." Revista Interin 10.2 (2011).
} 
conjuntura em que escreveu a obra Brasil Diferente, em 1955, dedicada ao governador Bento Munhoz da Rocha Neto, cuja produção intelectual veremos brevemente mais à frente. Wilson Martins ainda seria professor titular de literatura na Universidade de Nova Yorque de 1965 a 1991. Publicou grandes obras, dentre elas a mais famosa foi a História da Inteligência Brasileira. Foi reconhecido como o maior crítico literário do Brasil, ganhando diversos prêmios, sendo famoso por ler e fazer a crítica dos livros no calor do momento, no momento em que eram publicados. Wilson Martins foi casado com Ana Schmidt Martins, descendente da imigração alemã. Casaram na década de 1940 e não tiveram filhos. As pesquisas sobre suas famílias ainda estão em andamento, faltando lacunas a serem preenchidas. Tinham como sobrinhos Rosimeri Guazi e João Luiz Guazi ${ }^{5}$.

Já Nestor Vítor nasceu em Paranaguá, em 12/04/1868, filho de Joaquim Moreira dos Santos e Maria Francisca Mendonça dos Santos. Em 1885 se mudou para Curitiba. Em 1887, foi um dos fundadores do Clube Republicano de Paranaguá. Foi Secretário da Confederação Abolicionista do Paraná, cujo presidente era o major Sólon Ribeiro. Em 1888 começa amizade com Emiliano Pernetta, amizade essa que vai perdurar pelo resto de suas vidas. Foi para o Rio de Janeiro, onde participou do movimento a favor da proclamação da República, e onde conheceu o também literato Cruz e Souza. Nestor Vítor, como ainda veremos adiante, andava em meio a altos literatos, políticos, intelectuais, ou seja, pessoas que possuíam altos níveis de capitais, principalmente o capital intelectual. Foi ativo politicamente. Voltou para Curitiba, juntando-se a Domingos do Nascimento e Leôncio Correa na oposição a Vicente Machado. Depois, retorna ao Rio de Janeiro apoiando o contra-golpe de Marechal Deodoro. Em 1892, casou com Dona Catarina Alzira Coruja, tornando-se dessa forma cunhado de Emílio de Menezes. Em 1901 foi para a Europa, onde, em Paris, foi preceptor dos filhos do Barão do Rio Branco, com emprego na embaixada brasileira. Voltando ao Brasil, foi professor no Colégio Dom Pedro II e na Escola Normal. Em 1908, representou o Paraná na Convenção Nacional que indicou Rui Barbosa candidato de oposição à Presidência da República. Em 1912 iniciou a redação de A Terra do Futuro, a convite do governador do Estado. Fundou e participou de grupos com Rui Barbosa, José Veríssimo, Rocha Pombo, Graça Aranha, entre outros. Em 1917 foi eleito Deputado pelo Congresso Legislativo do Paraná, em 1918, nomeado vice-diretor da Escola Superior de Comércio. Em 1923, recebeu o

5 Disponível em http://www.gazetadopovo.com.br/caderno-g/gente/morre-viuva-de-wilson-martins-aos-88-anosd4w654h25kc05bo4gw4fk6c7i. Acessado em 30/04/17. 
título da Ordem da Coroa de Leopoldo da Bélgica e Cavaleiro da Legião de Honra da França. Em 1928, foi eleito membro da Academia Paranaense de Letras. Foi crítico militante no jornal "O Globo". Faleceu em 13 de outubro de $1932^{6}$.

Por essas origens, podemos entender, em partes, o porquê das ideias por eles vinculadas. Descendentes de europeus, convivendo no meio da elite paranaense em suas respectivas épocas, os literatos, em uma conjuntura em que se buscava a construção da identidade paranaense, optaram por destacar sociologicamente a influência europeia no Paraná, como um fator positivo. Frutos de suas escolhas, suas obras acabaram sendo muito seletivas, excluindo da visibilidade outros povos e culturas que também construíram o Estado paranaense.

Nestor Vítor, como um dos líderes do simbolismo no Paraná, contestava a visão técnicoanalítica do mundo, se afastando da crítica cientificista. Valorizava as impressões, a sensibilidade, a poesia. Foi nesse sentido que escreveu a obra A Terra do Futuro, como um livro de viagem, em que descreve as paisagens naturais paranaenses com grande entusiasmo, ao mesmo tempo em que recorria à história (oficial) para destacar o Estado como não sendo apenas mero coadjuvante em relação ao resto do país. O próprio título da obra já dá uma grande pista sobre o caráter positivista adotado pelo autor, que, como vimos em sua trajetória republicana, aposta no progresso como a grande salvação para o futuro, elogiando os grandes projetos e construções em curso, que contribuiriam para o crescimento econômico da região. Analisa e trás dados estatísticos econômicos, visita fazendas, colônias, fábricas, discorre sobre os engenhos de erva-mate. O tempo todo faz elogios, em seus diálogos construídos, aos projetos do presidente da província Carlos Cavalcanti, homem que o convidou a escrever a obra. O que impressiona na obra é falta de críticas à escravidão, a falta de algum sentimento para falar desse fenômeno (considerando que esse era seu método de escrita): "Mineração, depois indústria do mate, lavoura de cana e fabricação de aguardente, realizadas em vantajosas condições, com o braço escravo, vinham completar o simpático quadro de atividade e florescimento que então por toda parte ali se podia observar"7. Ou seja, se reconhecia a existência da escravidão no Paraná, mas não como um fenômeno de importância ou mesmo relevância, na medida em que essa foi uma das raras menções durante seu texto, em contraste com a grande análise feita da imigração europeia e seus grandes feitos.

\footnotetext{
${ }^{6}$ Vítor, Nestor. A terra do futuro: impressões do Paraná. Editora Farol do Saber. Curitiba, 1996.

${ }^{7}$ Idem, p. 40.
} 
Diferentemente dessa abordagem, temos a de Wilson Martins, em Brasil Diferente, no qual defende a inexistência da escravidão no Paraná, ou como um aspecto tão sem relevância que não merecia ser levado em consideração, na medida em que, para o autor, a escravidão não constituía a base da economia na província, ficando apenas no serviço doméstico. Martins, baseando sua obra em Casa Grande \& Senzala, de Gilberto Freyre, afirma que no Paraná não havia negros, índios, tampouco portugueses, e isso era o que diferenciava o Estado em relação às outras regiões do país, contrapondo na maioria das vezes com o Nordeste. O belo tipo físico do brasileiro do Paraná, se distinguiria dos demais brasileiros "por um traço de fundamental importância: não se misturava com o negro, existente em reduzidíssimo número em toda a província no decorrer da sua história, e que por isso não chegou a invadir sexualmente os hábitos desses rústicos senhores" ${ }^{\prime \prime}$. Para o autor, ao lado da imigração, é a inexistência da grande escravatura o aspecto mais característico da história social do Paraná. Ou seja, ao mesmo tempo em que afirmava a contribuição branca, negava a presença negra. Justificava isso pela ausência de grandes plantações agrícolas, e, por ser uma escravatura urbana, não havia o ambiente "senzalesco" como em outras regiões. Porém, como nas tabelas que o próprio autor expõe, a situação não era bem assim. Em Castro, no ano de 1815, por exemplo, a população era de 5801 habitantes, com 1073 escravizados $^{9}$. Na época do primeiro presidente da província, Zacarias de Góes e Vasconcelos, havia 62 mil habitantes, sendo que cerca de um sexto eram de pessoas escravizadas ${ }^{10}$. Citando Fugman, afirma que na zona rural, no trabalho com o mate, os negros eram tão preguiçosos quanto seus donos, e passavam o dia inteiro deitados dentro de casa. Como mais tarde vai demonstrar Octavio lanni ${ }^{11}$, o que se passou era o contrário, as vilas de Curitiba e Paranaguá, as primeiras a serem fundadas, foram fundadas com base na mão-de-obra escravizada, pois eram tropeiros que viriam pra essa região, procurando ouro, prata e mais cativos para escravizarem, isso tudo contando já com trabalho escravizado nas suas incursões. Mas a argumentação de Wilson Martins se dá com base na independência da província, em que o Paraná deixa de ser comarca de São Paulo em 1853. O fim do tráfico de escravizados se deu em 1851, em um processo

\footnotetext{
${ }^{8}$ Martins, Wilson. Um Brasil diferente: ensaio sobre fenômenos de aculturação no Paraná. Vol. 16. TA Queiroz, 1989, p. 141.

${ }^{9}$ Idem, p.142.

${ }^{10}$ Idem, p. 145.

${ }^{11}$ Ianni, Octávio. As metamorfoses do escravo: apogeu e crise da escravatura no Brasil meridional. Hucitec, 1988.
} 
de embranquecimento que já vinha ocorrendo durante todo o século $X I X$, que fez com que se mandasse praticamente todos os escravizados do Paraná para trabalhar nos cafezais de São Paulo12. Para Martins, "quando se apelou para a generosa bondade paranaense, a libertação precipitou-se, fez-se sem ruído e sem violências. A emancipação a 13 de maio de 1888 encontrou quase tudo feito ${ }^{13 "}$. E defendia "que o negro, sem o dinamismo reprodutivo que se observou em outras províncias brasileiras, sempre sofreu, e continua sofrendo, no Paraná, da tendência a desaparecer" 14 .

Essa questão sempre esteve em sintonia com a política de imigração. Analisando os relatórios dos diversos presidentes da província, Martins observa uma continuidade na política de imigração inaugurada por Zacarias de Góes e Vasconcelos, o primeiro presidente, em 1853. Para o povoamento da Província, fez uma política de atrair o imigrante estrangeiro (leia-se europeu), em que via o "trabalhador", o "técnico" o "agricultor" de que a província precisava. Então incentivou a criação de núcleos de colonização, grande parte de iniciativa particular. Wilson Marins elogia grandemente as iniciativas colonizatórias feitas pelos governos que o procederam, com políticas de incentivo aos imigrantes, como grandes empréstimos (até para construírem fábricas), terras, moradias, construiu estradas, tudo com um bom prazo para o retorno financeiro. O problema não é dar incentivo às pessoas, a questão é: porque não foram dados esses incentivos para a população negra que aqui estavam? Segundo lanni, a população escravizada chegou a ser metade da população de Curitiba, e foi ela que construiu a maioria das estradas no começo da abertura de caminhos na Província.

De qualquer forma, essas políticas resultaram no que Wilson Martins chamou de o "homem paranaense", com sua fisionomia humana particular e típica, com uma variedade étnica e amálgama progressiva de povos. Ou seja, o Paraná é uma grande miscigenação de povos, sem discriminação, mas são apenas povos europeus. Seria um "polígono irregular de sete lados, em ordem decrescente: polonês, ucraniano, alemão, italiano, os 'pequenos grupos', o índio e o negro,

\footnotetext{
12 Oliveira, Márcio. "O “Brasil diferente" de Wilson Martins." Caderno CRH 18.44 (2005): 215-221.

${ }^{13}$ Martins, op.cit.p. 144.

14 Idem, P.146.
} 
estes últimos em proporção praticamente insignificante" ${ }^{15}$. Isso seria, segundo o autor, uma representação do ponto de vista cultural, mais que biológico ou biográfico.

Essa concepção de Paraná "europeu" já estava presente em Nestor Vítor que, em sua viagem descrevendo a bela paisagem paranaense, que lembrava o norte da Europa, também descreve acentuadamente a contribuição da imigração europeia no desenvolvimento da civilização paranaense, mas não só no aspecto cultural. Ao descrever a subida da Serra: " o que deliciosamente ali nos impressiona são as coradas e alegres crianças, tanto mais quando, na sua maior parte, ela tem cabelos louros e olhos azuis. Já começamos aqui a encontrar-nos com a nova sub-raça paranaense, por enquanto ainda quase toda no planalto, mas que dentro em pouco dominará pelo Estado inteiro, população cujo fundo é constituído me muito pela corrente imigratória europeia, principalmente polaca, alemã e italiana, que continua a encaminhar-se numerosa para lá" 16 .

A superioridade da civilização europeia está presente com muita frequência nas duas obras, explicada pela urbanização e industrialização. Stuart Hall, ao discorrer sobre o multiculturalismo na Inglaterra ${ }^{17}$, afirma que a visibilidade de comunidades étnicas questionou a "homogeneidade" da cultura britânica e do "ser inglês" enquanto etnia, gerando uma crise de identidade nacional. E isso vem sendo feito em relação ao Paraná, na medida em que as culturas outrora excluídas ou invisibilizadas têm conseguido colocar esse debate, que ainda não tem a força para se sobrepor ao pensamento do Paraná ser um estado "europeu", mas que fica cada vez mais necessário gerar essa crise de identidade no âmbito regional, para que sejam valorizadas as culturas não-brancas que construíram e trabalharam muito nesse Estado. Para Hall, a configuração de "etnia" traz um deslocamento epistêmico, na medida em que "raça", não é uma categoria científica, mas uma construção política e social. É a categoria discursiva em torno da qual se organiza um sistema de poder socioeconômico, de exploração e exclusão. O racismo tenta justificar as diferenças sociais e culturais que legitimam a exclusão racial em termos de distinções

\footnotetext{
${ }^{15}$ Idem, P. 122.

${ }^{16}$ Vítor, op.cit. p. 65.

${ }^{17}$ Hall, Stuart. Da diáspora: identidades e mediações culturais. Vol. 93. Editora UFMG, 2006, p. 68.
} 
genéticas e biológicas, ou seja, na natureza ${ }^{18}$. Já a "etnicidade" gera um discurso em que a diferença se funda sob características culturais e religiosas e frequentemente se opõe a raça, mas numa oposição binária simplista. Os estigmatizados pela etnia são vistos como culturalmente inferiores, mas também caracterizados em termos físicos, mas o referente biológico é feito de forma mais indireta. O que há, na realidade, para Hall, uma "cadeia de equivalência" entre o registro sociocultural e o biológico. Não constituem dois sistemas distintos, mas dois registros do racismo. Para o autor, "racismo existe onde há uma associação dessas duas principais estratégias, cuja combinação peculiar depende das especificidades da experiência, do momento histórico e da preferência individual”19. Dessa forma, veremos como o discurso de construção da identidade cultural regional paranaense se dá, a partir dos dois principais autores trabalhados, utilizando-se da metodologia de Stuart Hall para identidades culturais nacionais, adaptando para o contexto regional paranaense.

Para Stuart Hall, as culturas nacionais são comunidades imaginadas, constituindo uma das principais fontes de identidade cultural ${ }^{20}$. E, ao contrário do pensamento de muitas pessoas, não fazem parte da nossa natureza, não são coisas com as quais nascemos. São formadas e transformadas no interior da representação. A nação é não somente a entidade política, mas um sistema de representação cultural, algo que produz sentidos. As pessoas não são apenas cidadãos legais, mas participam da ideia da nação, do sentimento de identidade e lealdade. Não são apenas instituições culturais, mas são símbolos e representações. Uma cultura nacional é um discurso, "um modo de construir sentidos que influencia e organiza tanto nossas ações quanto a concepção que temos de nós mesmos"21. Os sentidos constroem identidades, as estórias e memórias conectam o presente com o passado, e imagens são construídas.

Dentre as estratégias para construir essas representações de senso comum, destaco a narrativa da nação, ou, no caso, a narrativa regional paranaense, tal como é contada e recontada nas histórias e nas literaturas, na mídia e na cultura popular. "Estórias, imagens, panoramas,

\footnotetext{
${ }^{18}$ Idem, p. 69.

${ }^{19}$ Idem, P. 71.

${ }^{20}$ Hall, Stuart. "A identidade cultural na pós-modernidade." Rio de janeiro: DP\&A (2000), p. 47.

${ }^{21}$ Idem, P. 50.
} 
cenários, eventos históricos, símbolos e rituais nacionais que simbolizam ou representam as experiências partilhadas, as perdas, os triunfos e os desastres que dão sentido à nação. [...] dá significado e importância à nossa monótona existência, conectando nossas vidas cotidianas com um destino nacional que preexiste a nós e continua existindo após a nossa morte" ${ }^{22}$. Dá uma ideia de tradição, de herança, de continuidade. É importante destacar aqui que o fato de se construir uma identidade regional não afasta a construção da identidade cultural nacional, também presente nas mentalidades paranaenses. Porém, com a independência do Paraná enquanto Província e em relação a São Paulo, surgiu um movimento de se perguntar quem são os paranaenses, quais são as peculiaridades do estado do Paraná em relação ao restante das regiões brasileiras? O paranismo, enquanto movimento artístico e intelectual ${ }^{23}$, reuniu diversos artistas e intelectuais que se dedicaram nessa questão, muitos deles exaltando as riquezas naturais do Estado.Várias formas de pensamento contribuíram para esse movimento não-homogêneo.

De qualquer forma, as obras de Nestor Vítor e de Wilson Martins se encaixam na esteira desses acontecimentos. A Terra do Futuro, de 1912, mais presente nessa conjuntura, e Brasil Diferente, de 1955, aparecendo momentos depois. Ambos têm papel fundamental nessa construção do Paraná enquanto "comunidade imaginada", forjando o senso comum que ainda hoje tem muita força na cultura política paranaense. Ambos circulavam em meio à elite paranaense, ficando muito próxima, por exemplo, as visões de mundo de Wilson Martins e de Bento Munhoz da Rocha Neto, para quem o primeiro dedicou sua obra. Bento Munhoz da Rocha Neto era governador do Paraná à época da publicação de Martins, e, segundo Maria Julieta Weber, um intelectual profundamente envolvido nas lutas simbólicas, nesse momento que era de afirmação regional paranaense. Era descendente da elite ervateira, de famílias tradicionais do poder do Paraná. Rocha Neto escrevia que o sul era uma "mancha loira" em meio ao restante do país, e exaltava as terras paranaenses, defendendo que seu povo tivesse orgulho do seu Estado.

\footnotetext{
22 Idem, P.53.

${ }^{23}$ Cordova, Maria Julieta Weber. Bento, Brasil e David: O discurso regional de formação social e histórica paranaense. Editora UFPR. Curitiba, 2016.
} 


\section{CONSIDERAÇÕES FINAIS}

Pudemos observar até aqui, nesse trabalho, que a ideia de que o Paraná é um estado "europeu" não é natural, nascida com a população paranaense. Essa ideia foi construída, na literatura, com expoentes intelectuais, sendo os principais Nestor Vítor e Wilson Martins, ambos os autores de peso com repercussão nacional, com muitos títulos, prêmios e obras respeitadas. Na política, foi construído a partir de ações políticas dos seus governantes desde o primeiro, Zacarias de Góes e Vasconcelos. Afinal, como demonstram os estudos de Ricardo Costa de Oliveira ${ }^{24}$, a fundação das vilas e a criação dos aparelhos de Estado no Brasil são frutos da continuidade da expansão do Estado português, consequentemente seus governantes vão fazer políticas colonizatórias. A peculiaridade do Paraná, segundo o mesmo Ricardo Costa, é que foi um Estado escolhido pelos estrategistas do Brasil Império para ser um modelo de europeização e branqueamento para o resto do país. Nesse sentido, os literatos contribuíram para legitimar as ações políticas da classe dominante brasileira e paranaense.

Até aqui, muitas dessas noções podem ser tidas como fato para grande parte dos pesquisadores em Ciências Sociais, mas a continuidade da pesquisa abre margem para uma série de perguntas, como por exemplo: qual a relação dessa construção de identidade paranaense com o "racismo científico" do final do século XIX? Qual a intenção dos autores em escrever essas obras? Eles tinham intenção própria, ou estavam seguindo o fluxo de seus respectivos tempos e posição social, o habitus de sua classe?

Esse tipo de pesquisa é de fundamental importância para o conhecimento do Estado do Paraná e para sua identidade, essencial para o posicionamento político e compreensão da história regional. Vão crescendo as pesquisas sobre essa temática, e ainda temos muito por avançar. As pesquisas sobre as famílias dos autores ainda são lacunas a serem preenchidas posteriormente para o aprofundamento das questões.

\footnotetext{
${ }^{24} \mathrm{O}$ silêncio dos vencedores.
} 


\section{REFERÊNCIAS}

Moraes, Pedro Rodolfo Bodê de, and Marcilene Garcia de Souza. "Invisibilidade, preconceito e violência racial em Curitiba." Revista de Sociologia e Política 13 (1999): 7-16.

Quadros, Claudia Irene de, and Mônica Kaseker. "Wilson Martins: das ondas do rádio às críticas literárias." Revista Interin 10.2 (2011).

Vítor, Nestor. A terra do futuro: impressões do Paraná. Editora Farol do Saber. Curitiba, 1996.

Martins, Wilson. Um Brasil diferente: ensaio sobre fenômenos de aculturação no Paraná. Vol. 16. TA Queiroz, 1989.

Ianni, Octávio. As metamorfoses do escravo: apogeu e crise da escravatura no Brasil meridional. Hucitec, 1988.

Hall, Stuart. Da diáspora: identidades e mediações culturais. Vol. 93. Editora UFMG, 2006.

Hall, Stuart. "A identidade cultural na pós-modernidade." Rio de janeiro: DP\&A (2000).

Cordova, Maria Julieta Weber. Bento, Brasil e David: O discurso regional de formação social e histórica paranaense. Editora UFPR. Curitiba, 2016. 